Document downloaded from:

http://hdl.handle.net/10251/176246

This paper must be cited as:

Rius-Sorolla, G.; Maheut, J.; Estelles Miguel, S.; García Sabater, JP. (2021). Operations planning test bed under rolling horizons, multiproduct,multiechelon, multiprocess for capacitated production planning modelling with strokes. Central European Journal of Operations Research. 29:1289-1315. https://doi.org/10.1007/s10100-020-00687-5

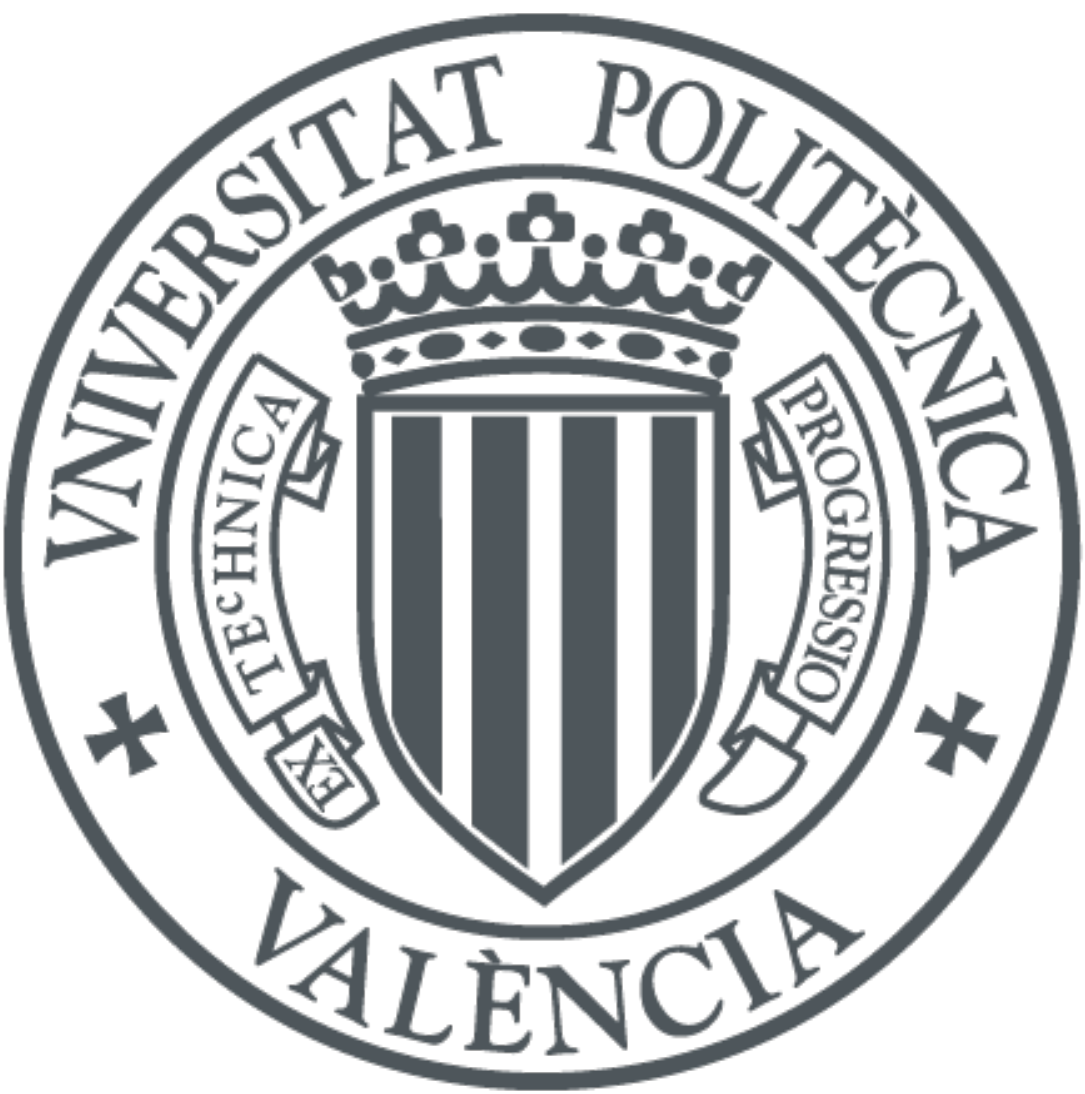

The final publication is available at

https://doi.org/10.1007/s10100-020-00687-5

Copyright Springer-Verlag

Additional Information 


\title{
Operations planning test bed under rolling horizons, multiproduct, multiechelon, multiprocess for capacitated production planning modelling with strokes
}

\author{
G. Rius-Sorolla $^{1}$ (D) J. Maheut ${ }^{1} \cdot$ S. Estellés-Miguel ${ }^{1} \cdot$ J. P. García-Sabater ${ }^{1}$
}

\begin{abstract}
One of the problems when conducting research in mathematical programming models for operations planning is having an adequate database of experiments that can be used to verify advances and developments with enough factors to understand different consequences. This paper presents a test bed generator and instances database for a rolling horizons analysis for multiechelon planning, multiproduct with alternatives processes, multistroke, multicapacity with different stochastic demand patterns to be used with a stroke-like bill of materials considering production costs, setup, storage and delays for operations management. From the analysis of the operations planning obtained from this test bed, it is concluded that a product structure with an alternative process obtains the lowest total cost and the highest service level. In addition, decreasing seasonal demand could present a lower total cost than constant demand, but would generate a worse service level. This test bed will allow researchers further investigation so as to verify improvements in forecast methods, rolling horizons parameters, employed software, etc.
\end{abstract}

Keywords Rolling horizon · Scheduling · GMOP · Supply chain management

\section{Introduction}

In operations planning models research, it is necessary to have a sufficiently broad repertoire of instances that includes the different situations to be studied. A test bed allows the behaviour of dependent variables to be analysed based on the different levels of the independent variables and the elements common to all the selected instances or parameters (Xie et al. 2003). Dependent variables refer to those obtained from the pro-

$\bowtie$ G. Rius-Sorolla greriuso@upv.es

1 Dpto. de Organización de Empresas, Universitat Politècnica de València, Camino de Vera s/n, 46022 Valencia, Spain 
posed solutions and allow different solutions to be compared (Narayanan and Robinson 2010). The parameters will be the different elements to be selected in each model, and the independent variables define the characteristics of each situation included in the test bed. Adequate instances should be selected to analyse the consequences on the dependent variables of these independent variables and their combination. The literature contains numerous repertoires of instances, such as Stadtler (2000), whose later work incorporates new situations (Stadtler 2003). Nevertheless, to the best of our knowledge, the multisite, multistage, capacitated lot-sizing, with lead times and an alternative operations test bed has not yet been found.

The alternative operation is frequently found in industry (Maheut et al. 2012). The formulation proposal done with Generic Materials and Operations Planning (GMOP) (Garcia-Sabater et al. 2013) allows work to be done with alternatives operations based on the strokes concept. Strokes represent any transforming, transporting or consuming operation and allow modelling to optimise the most appropriate operation alternatives. Modelling with strokes enables the bill of materials (BOM) and the bill of process (BOP) to be managed together. It also permits a model to be represented with parallel processes, alternative packaging management, the decomposition of products and other possibilities inherent to using strokes. It is claimed to be more versatile than the Gozinto structure (Maheut 2013). A test bed with strokes is available (CoronadoHernández 2016), but with no alternative process.

Rolling horizons should be considered in an adequate test bed. The heuristic approach of rolling horizons is a common tool in operations planning in both industry and academic environments in multiperiod problems (de Sampaio et al. 2017). The main reasons are limited information about the future, its uncertainty (Baker 1977) and the available computational capacity to make decisions in the required time (Araujo et al. 2007). In a typical scenario, a model is solved and only the first period's decisions are put into practice (Baker 1977). This approach enables to respond to problems related to inventory management, production planning, scheduling, location of plants, among others (Chand et al. 2002). The use of rolling horizons helps to relax large problems by decomposing them into smaller planning units (Garcia-Sabater et al. 2009; Lv et al. 2017; Ramezanian et al. 2017; Rodriguez et al. 2017; Zulkafli and Kopanos 2017). It should be noted that optimal approaches for each horizon act as heuristics and cannot guarantee that the proposed solution is optimum (Karimi et al. 2003). A recent review of rolling horizons can be found in Sahin et al. (2013).

The main contributions of the work are to present an instance generator together with an instance database with alternative process based on the strokes concept for a rolling horizon procedure and a brief overview of some test bed elements available in the literature. These situations will allow subsequent analyses of production planning procedures by considering various degrees of uncertainty, different demand patterns, and distinct BOM structures. Instances are multiproduct, multilevel, multistroke with several capacity limitations, and also with information on storage costs, setup costs, processes costs and penalisation for delays.

The rest of the paper is structured as follows: first, an introduction to the basic concepts of rolling horizon is presented; second, a brief overview of the different test bed elements found in the literature is presented; thirdly, a test bed with common elements is described; fourth, the independent elements in instances are introduced; 


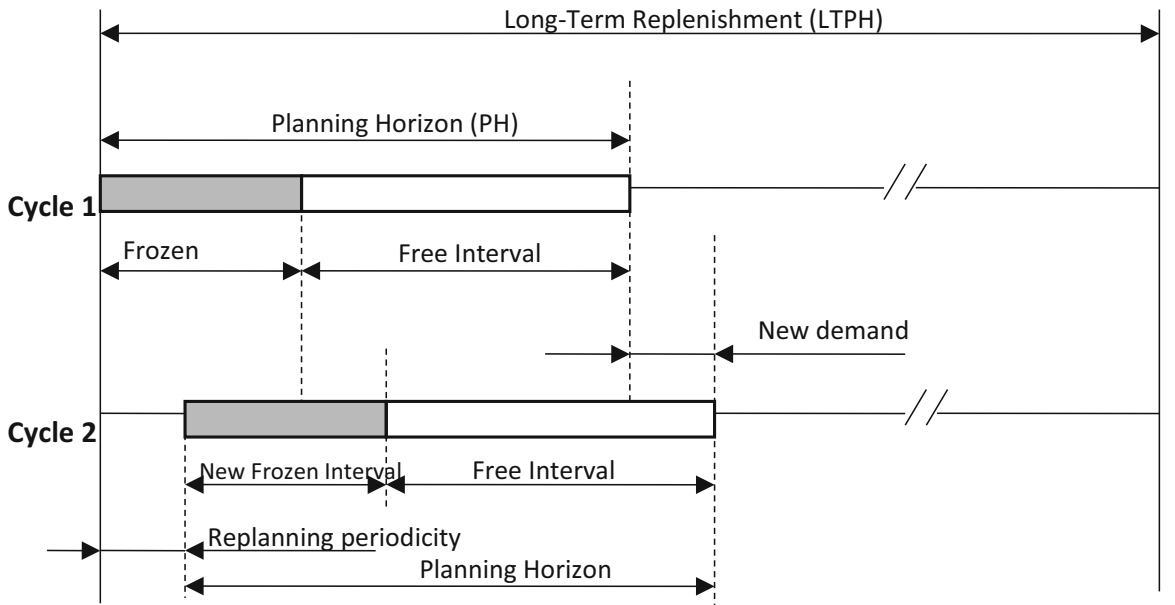

Fig. 1 Planning concepts of rolling horizons. Long-TERM PLANNING HORIZON (LTPH), planning horizon (PH), Frozen interval (FI), replanning periodicity (RP). Source: adapted from Sahin et al. (2013)

fifth, a characterisation of the test bed is offered; sixth, some measurement elements are provided; seventh, a resolution of the test is done with the analysis of the total cost and service level distribution; last, some conclusions and future works are provided.

\section{Basic concepts and terminology of rolling horizons}

The first explicit academic work on Rolling Horizons (RH) dates back to 1977, as contributed by Cao (2015). With a set of experiments, Baker (1977) suggested that average RH performance could produce low-cost results within $1 \%$ optimality. The essential elements when applying RH are found in Fig. 1.

The term Long-Term Planning Horizon (LTPH) refers to the entire demand horizon to be analysed. It is not usually planned throughout the LTPH for several reasons. Its modelling cannot be assumed with the computational capacity available in the time required to make decisions (Araujo et al. 2007). Future information from a certain period is not very reliable or contains considerable uncertainty, which does not allow interest to be calculated (Karimi et al. 2003).

For these reasons, the RH approach is limited to solve shorter time periods. The spread of demand to be included is called Planning Horizon (PH). Baker (1977) concluded that for those constant demand or trend profiles without seasonal effects, the most appropriate forecast window, $\mathrm{PH}$, must be an integral multiple of the time that derives from the EOQ (Economy Order Quantity). The longer the PH, the lower the total planning costs obtained, but instability in planning increases (Sahin et al. 2013) and computational requirements also increase. With stochastic demand, Cao (2015) recommended extending the length of PH to reduce planning costs. However, other authors (Lalami et al. 2017) emphasise that its prolongation improves performance when demand is deterministic, but it degrades when demand is uncertain. Xie et al. 
(2003) recommended extending the PH as it improves total planning costs, stability and service level when capacity limitation, demand uncertainty and multiproduct exist. Nedaei and Mahlooji (2014) stated that the PH should be at least fivefold longer than the natural order cycle from the EOQ. De Araujo et al. (2007) recommended selecting fewer demand periods on the $\mathrm{PH}$ as it is a heuristic procedure with uncertainty about the demand forecast. Fewer periods enable more agility in solving models and allow actions to be proposed in real time (Hsu and Yang 2017).

Furthermore, the choice of the $\mathrm{PH}$ means that mathematical models interpret that there will be no further requirements of stock or operations after the selected demand periods. This effect is called the "truncated horizon effect" (Federgruen and Tzur 1994). In the literature, there are different approaches to overcome this effect. Stadtler (2000) proposed adjusting the fixed replacement costs during the final PH periods. Fisher et al. (2001) suggested adding a final inventory requirement. Garcia-Sabater et al. (2012) recommended the final inventory being obtained by solving aggregate planning.

The period during which the planning proposal will not be modified, regardless of any possible new information appearing, is called Frozen interval (FI). The planning of these periods is used in industry to calculate material requirements; e.g. it allows to send firm orders in the supply chain (Sahin et al. 2013). The choice of FI is a balance struck among planning stability, total costs and service level (Lalami et al. 2017). It has a stronger impact on total costs than the PH (Narayanan and Robinson 2010). The freezing of planning can refer to freezing either certain periods or certain planning orders (Nedaei and Mahlooji 2014). Costs are higher if the method based on freezing periods is used instead of the freezing order method (Omar and Bennell 2009). However, as multiple end elements appear in instances, and as each final element has its own ordering cycle, it is more difficult to implement the freezing method based on freeze orders.

The term Replanning periodicity (RP) refers to periods between planning cycles. Each new cycle incorporates new demand information and the execution status of the previous planning cycle. In industry, it is normally replanned weekly, or even daily, to incorporate new orders (Rafiei et al. 2012), despite some academic studies indicating that the best balance between costs and service level should be replanning biweekly at all types of volatility level in demand (Barrett and LaForge 1991). However, empirical research shows that those companies which reprogramme more frequently obtain better results (Hozak and Hill 2009). This continuous planning process allows future demand to be anticipated in the decisions of the current period while postponing future decisions as late as possible. Xie et al. (2003) concluded that RP must equal FI to achieve better behaviour in multiproduct, capacitated and with uncertainty in demand. Omar and Bennell (2009) mentioned that replanning frequency does not affect total costs if there are no significant differences between unit costs and setup costs, and if demands are non-volatile, constant or increasing or seasonal in their instances.

Other models include different costs, such as the costs associated with demand forecasting (Kleindorfer and Kunreuther 1978). Modelling per se allows a balance to be struck between the appropriate $\mathrm{PH}$ and the costs associated with increasing the demand periods to be forecasted (Sethi and Sorger 1991). However, this is beyond the purpose and scope of the present work. 


\section{Brief overview of test bed elements in the literature}

All the elements presented in the RH could be selected parameters or independent variables for the test bed. Other elements required to solve the mathematical models are the criteria to select a proposal for each horizon (accepted tolerance, time limit, software and computer used, etc.) (Meindl and Templ 2012) or any symmetric breaking actions (Jans 2009).

The elements that define test bed factors are independent variables. They establish the characteristics of the instances to be evaluated in their consequences for dependent variables. As the initial inventory can influence the performance of a lot-sizing problem (Trigeiro 1987; Kimms 1997) established the structures, external demand, capacity limits, holding cost, setup costs and initial inventory of multilevel lot sizing and scheduling problems as test bed elements. Karimi et al. (2003) characterised an RH lot sizing test bed with number of products, number of levels, available capacity of resources, demand, setup structure (cost and time), production cost, lead time, inventory shortage cost and holding (cost and deterioration time of items). Multilevel systems were further distinguished by the type of product structure, which includes serial, assembly, disassembly in general, or MRP systems (Karimi et al. 2003). The production cost could be independent or dependent on the production amount. Xie et al. (2003) defined independent variables as environmental factors with variations in demand, product mix, capacity tightness, maximum natural ordering cycle and unit shortage cost. The maximum natural ordering cycle is defined by the inventory carrying cost and production setup cost/ordering cost.

The different defined costs and times can be independent or dependent on the sequence. Wolsey (2002) identified sequence-dependent costs and/or times as still lacking tight mixed integer programming formulations that would permit optimal solutions for realistic sized problem instances using standard optimizers. The setup changeover from one material to another consumes capacity time insofar as it can depend on the sequence in which materials are processed. Meyr (2002) considered both sequence-dependent setup costs and sequence-dependent setup times. Based on a real industrial case, Tiacci and Saetta (2012) studied 23 items with a sequence dependent setup cost, but this also goes beyond the scope of this test bed.

Furthermore, problems can also have independent or dependent demand (Karimi et al. 2003). Independent demand is known when product demands are established directly from customer orders or market forecasts. The independent demand type is considered to be input to the problem model. In multilevel systems, a parent-component relation exists among items. The demand of components depends on parent orders. Dependant demand may also come from other variables, such as quantity discounts, trade credit, price discounts, volume discounts, common replenishment periods, etcetera (Kumar et al. 2016). Demand can be static, and may not change with time or be dynamic (Karimi et al. 2003). If demand is exactly known, it is termed deterministic. However if the demand is not known, it may follow some probabilities, and then it is called probabilistic (DeYong and Cattani 2016). Demand may contain some uncertainty that can be grouped as unknown variation, suspicious variation or known variation (Rafiei et al. 2014). In unknown variation, no advance information is avail- 
able, such as a sudden accident or strikes. For suspicious variation, some information is available, such as expected cancellations or demand fluctuation.

Different demand patterns have been used in test beds. Baker (1977) and Omar and Bennell (2009) proposed constant demands, linear trend, seasonal with sinus function and trend-seasonal as a combination of both. All these demands were modified with uniform random variation with zero mean as noise, Baker with a range of 75 and Omar et al. with a range of 200. Blackburn and Millen (1980) used normal and uniform distributions for demand. Carlson et al. (1982) added random uniform, normal, bimodal-normal variation for demand uncertainty. Zoller and Robrade (1988) proposed uniformly random distribution. Fisher et al. (2001) employed demand distributions, such as stationary demand distributions (uniform and normal), non-stationary demand distributions (seasonal demand with a normal disturbance term, linearly increasing, and linearly decreasing demand), and correlated demand distribution. The correlated demand pattern is performed by a standard Markov process. DeYong and Cattani (2016) proposed designing distributions to provide examples of symmetric, leftskewed and right-skewed demand, while maintaining an identical mean and variance. Demand patterns can also present some periods without demand or lumpy demand conditions, which frequently occur in MRP settings (Blackburn and Millen 1980; Nedaei and Mahlooji 2014) or are also called demand density (Narayanan and Robinson 2010). For demand with normally random variation, negative values subsequently change to zero (Simpson 2001). Demand can also be divided between products. Xie et al. (2003) defined product-mix variation as the average proportion of demand for individual item in the normal random noise component of the product-mix proportion for five products.

In addition, numerical experiments can incorporate different demand forecast models. Zhao and Xie (1998) used two forecast methods in their test bed: the simple moving average (MA) model and Winters' mode (WM). Cao (2015) included different demand forecasts methods and recommends Poler and Mula (2011), who proposed an automatic selection method to better adapt different work settings and to reduce forecast errors. Forecast models are important parameters that influence lot-sizing problem performance (Prasad and Krishnaiah Chetty 2001).

In dependent variables, different elements have been used. Total cost has generally been studied and it has been evaluated as a ratio in relation to a total cost reference. Instability or nervousness has been measured by changes in the planned quantity in relation to the previous PH (Barrett and LaForge 1991; Omar and Bennell 2009), only by changes in quantity during the first planned period (Kimms 1997), or when replanning setup operations (Narayanan and Robinson 2010; Nedaei and Mahlooji 2014; Simpson 2001; Xie et al. 2003). Service level is measured as the percentage of the met end item demands (Barrett and LaForge 1991; Lalami et al. 2017; Xie et al. 2003; Zhao and Xie 1998). Other papers have studied the computer time required to obtain the solution (Araujo et al. 2007; Jans 2009; Lalami et al. 2017; Zoller and Robrade 1988).

The test model should incorporate some replicas to analyse the distributions of results. Blackburn and Millen (1980) used eight replications and Simpson (2001) contained ten replications. Xie et al. (2003) employed five runs to reduce random variables. DeYong and Cattani (2016) defined the experiment with 10 replications. However, it 


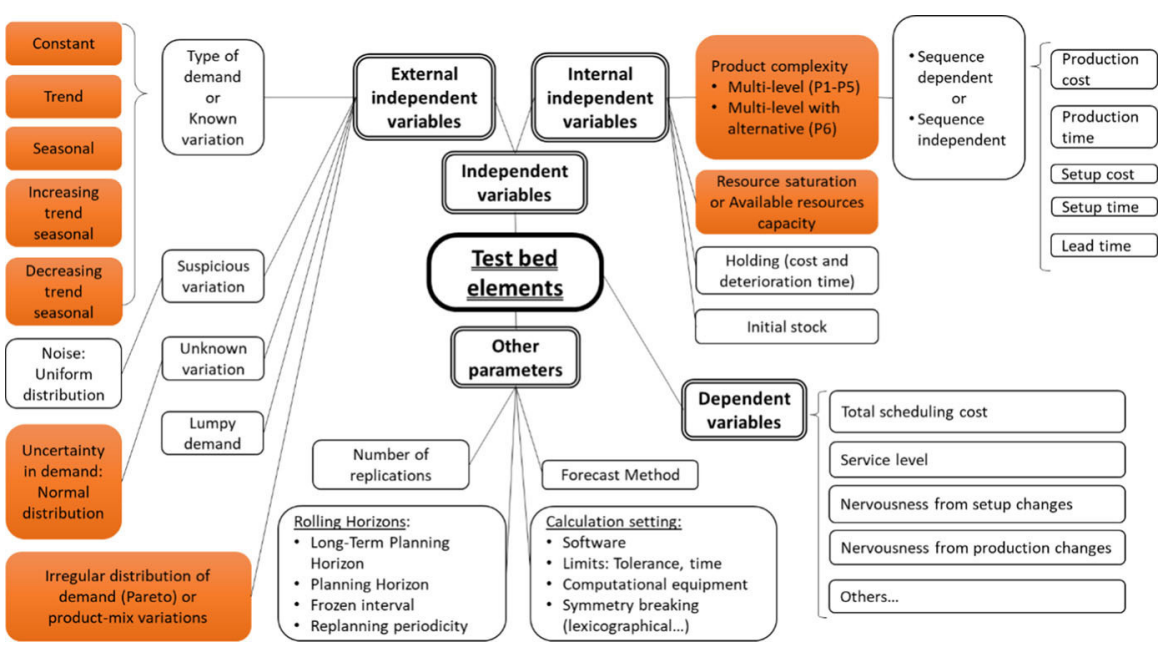

Fig. 2 Conceptual map of the test bed. Orange depicts the independent variables introduced into this test bed generator. Source the Authors

is more important to validate results than to increase the number of observations (Hair et al. 1999). A complete conceptual map of some different elements of the presented test beds are found in Fig. 2.

\section{Test bed generator proposal: common elements}

In this section, a test bed generator is proposed so that researchers can select different independent variable combinations. The elements common to all instances or the selected parameter is introduced. The following section presents five different factors. Experiments were planned for a 52-period LTPH divided into 8-period demand forecast horizons, the PH updated during each period with a new demand forecast period, the RP. Planning seeks to minimise the sum of storage costs, operations costs, setup cost and penalties for delays.

Given the importance of initial stocks levels (Behnamian and Fatemi Ghomi 2014), 12 previous periods were added with an initial stock of two periods at each product level. Therefore, the initial stock raised for each instance had no impact on the 52 periods of the analysis of instances. At the same time, seven more periods were added to the last planning cycle so that the simulation model would perceive continuity and avoid the "truncated horizon effect" for the last PH. Therefore, stocks were not left at zero at the end of simulation. In short, 71 demand periods were provided for the analysis of the 52 periods to run a maximum of $64 \mathrm{PH}$ cycles.

The storage costs, delay costs, preparation and execution costs of the stroke are seen in Table 1 . These costs are affected depending on whether they come close to the decision making $\left(\mathrm{t}_{1-8}\right)$ and weighted among the final products as they were presented as increasing and decreasing costs by DeYong and Cattani (2016). Table 2 shows that they are modified according to $t$ and $S K U i$ (Stock Keeping Unit of product $i$ ). The 
Table 1 Costs and common parameters. Source: according to previous works (Prasad and Krishnaiah Chetty 2001) and modified in line with defined levels

\begin{tabular}{llclc}
\hline Level & $\begin{array}{l}\text { Storage cost } \\
\left(\mathrm{H}_{\mathrm{i}}\right)\end{array}$ & $\begin{array}{l}\text { Setup cost } \\
\left(\mathrm{SC}_{\mathrm{k}}\right)\end{array}$ & $\begin{array}{l}\text { Stroke cost } \\
\left(\mathrm{CO}_{\mathrm{k}}\right)\end{array}$ & $\begin{array}{l}\text { Delay cost } \\
\left(\mathrm{CB}_{\mathrm{i}}\right)\end{array}$ \\
\hline 1 & 1 & 8000 & 2 & 3680 \\
2 & 0.1 & 4000 & 1 & 1840 \\
3 & 1 & 18,000 & 5 & 920 \\
4 & 2 & 4000 & 1 & 460 \\
5 & 1 & 8000 & 2 & 3680 \\
\hline
\end{tabular}

Table 2 Costs multiplying factors. Source: the Authors to reduce the symmetry

\begin{tabular}{|c|c|c|c|c|c|c|c|c|c|}
\hline $\mathrm{t}_{1}$ & $\mathrm{t}_{2}$ & & & $t_{4}$ & $t_{5}$ & & $t_{6}$ & $\mathrm{t}_{7}$ & $t_{8}$ \\
\hline 1.5 & 1.43 & & & 1.29 & 1.21 & & 1.14 & 1.07 & 1 \\
\hline $\mathrm{SKU}_{1}$ & $\mathrm{SKU}_{2}$ & $\mathrm{SKU}_{3}$ & $\mathrm{SKU}_{4}$ & $\mathrm{SKU}_{5}$ & $\mathrm{SKU}_{6}$ & $\mathrm{SKU}_{7}$ & $\mathrm{SKU}_{8}$ & $\mathrm{SKU}_{9}$ & $\mathrm{SKU}_{10}$ \\
\hline 1.5 & 1.44 & 1.39 & 1.33 & 1.28 & 1.22 & 1.17 & 1.11 & 1.06 & 1 \\
\hline
\end{tabular}

Table 3 Process parameters. Source: preparation according to Coronado-Hernández (2016)

\begin{tabular}{llcl}
\hline Resources & Required resource time $\mathrm{r}$ for stroke $\mathrm{k}\left(\mathrm{TO}_{\mathrm{kr}}\right)$ & Setup time $\left(\mathrm{TS}_{\mathrm{kr}}\right)$ & Lead time $\left(\mathrm{LT}_{\mathrm{k}}\right)$ \\
\hline $\mathrm{R} 1$ & 1 & 5 & 1 \\
$\mathrm{R} 2$ & 1 & 5 & 1 \\
$\mathrm{R} 3$ & 1 & 5 & 1 \\
$\mathrm{R} 4$ & 1 & 5 & 1 \\
R5 & 1 & 10 & 1 \\
\hline
\end{tabular}

Gozinto factor (the necessary subproduct units to generate a product) is unitary in all cases.

Each instance has 10 final products with an independent demand and four components per product with a dependent demand. The 10 final products of each instance take the same structure.

Each process required consuming one unit of time $\left(\mathrm{TO}_{\mathrm{kr}}\right)$ of stroke per unit of processed product in UT (units of time) per period; see Table 3. The setup $\left(\mathrm{TS}_{\mathrm{kr}}\right)$ consumes 5-10 UT of the used resource R1-R5, but independently of the operation sequence. Lead times $\left(\mathrm{LT}_{\mathrm{k}}\right)$ needed to perform all the operations are during one period in each resource; see Table 3.

\section{Independent elements in the instance generator proposal}

The independent variables introduced in the test bed are "product complexity" and "resources saturation" or available resource capacity as the internal variables. The external independent variables are "type of demand" (known and suspicious variation), 


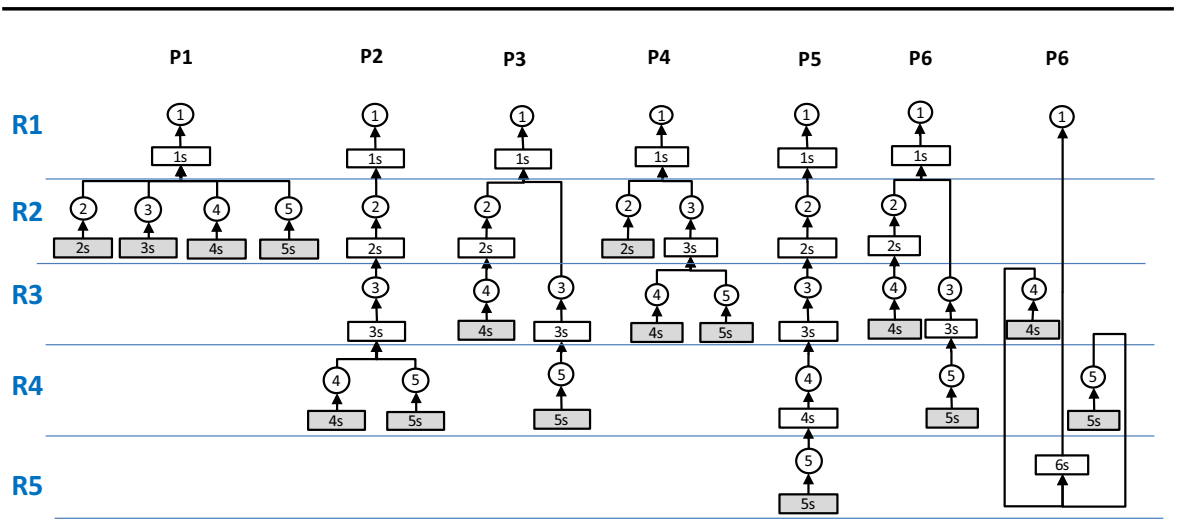

Fig. 3 Structures of the different product types. Source: the Authors based on Coronado-Hernández (2016) and own work

"irregular distribution of demand (Pareto)" and "uncertainty in demand" (unknown variation). They are all explained below.

\subsection{Factor of product complexity (BOM)}

The product complexity factor includes the different components needed to define the SKU, including its packaging and its physical location. Each instance takes one of the six material structures shown in Fig. 3 for its 10 final products. The first five structures have a unique composition, where each instance has 50 strokes. The sixth structure $P 6$ has an alternative for the same final product, so its instances have 60 strokes. The alternative process is found in industry, but cannot easily be incorporated into commercial MRP. A more complex alternative can be found, but this simple configuration may contribute to knowledge of its consequences on operation planning.

In Fig. 3 strokes are represented by squares and SKUs by circles. The purchasing strokes are shaded squares that do not use resources. Different product structures can be seen according to Coronado-Hernández (2016) to which the P6 configuration is added. The final product of $P 6$ can be made by stroke one or by the stroke six. The P6 configuration allows the influence of product structure to be analysed with alternative processes in operation planning objectives. An alternative process can be supported by the GMOP formulation. The GMOP formulation allows product structures with alternatives in processes as opposed to other formulations based on Billington et al. (1983) that require unique product structures for each final product. For clarity sake, the qualitative independent factor of the BOM can take the P1, P2, P3, P4, P5 and P6 values.

\subsection{Demand type factor}

This factor identifies the demand behaviour patterns over the periods. This independent factor includes demand patterns, such as constant demand (CC), increasing trend (TT), 
Table 4 Demand types. $D_{t^{\prime}}$ Total demand of all the 71 periods, $\mu_{t^{\prime}}$ constant total demand for each period, $\mathrm{Z}_{\mathrm{t}^{\prime}}$ uniform random noise. Source: the Authors according to Carlson et al. (1982), Omar and Bennell (2009) and own work

\begin{tabular}{ll}
\hline Demand type & Function \\
\hline Constant (CC) & $\mathrm{D}_{\mathrm{t}^{\prime}}=\mu_{\mathrm{t}^{\prime}}+\mathrm{Z}_{\mathrm{t}^{\prime}}$ \\
Trend (TT) & $\mathrm{D}_{\mathrm{t}^{\prime}}=\mu_{\mathrm{t}^{\prime}}+\mathrm{Bt}^{\prime}+\mathrm{Z}_{\mathrm{t}^{\prime}}$ \\
Seasonal (SS) & $\mathrm{D}_{\mathrm{t}^{\prime}}=\mu_{\mathrm{t}^{\prime}}\left(1+\sin \left(2 \pi \mathrm{t}^{\prime} / 52+\pi / 2\right)\right)+\mathrm{Z}_{\mathrm{t}^{\prime}}$ \\
Seasonal + trend (ST) & $\mathrm{D}_{\mathrm{t}^{\prime}}=\mu_{\mathrm{t}^{\prime}}\left(1+\sin \left(2 \pi \mathrm{t}^{\prime} / 52+\pi / 2\right)\right)+\mathrm{Bt}^{\prime}+\mathrm{Z}_{\mathrm{t}^{\prime}}$ \\
Seasonal-trend (SD) & $\mathrm{D}_{\mathrm{t}^{\prime}}=\mu_{\mathrm{t}^{\prime}}\left(1+\sin \left(2 \pi \mathrm{t}^{\prime} / 52+\pi / 2\right)\right)-\mathrm{Bt}^{\prime}+\mathrm{Z}_{\mathrm{t}^{\prime}}$ \\
\hline
\end{tabular}

$D_{t}$ is the total demand of each LTPH period; $\mu_{\mathrm{t}^{\prime}}$ is the average demand of each period $\mathrm{t}^{\prime}$ set at 500 units; $\mathrm{Z}_{\mathrm{t}^{\prime}}$ is the noise calculated by a random of uniform type of \pm 5 units. $\mathrm{B}_{\mathrm{t}^{\prime}}$ is the constant demand variation period by period, with a $50 \%$ variation of the total demand at the end of the 52 periods. For clarity sake, the qualitative independent factor of the demand type may take the CC, TT, SS, ST, and SD values

seasonality (SS), seasonality plus an increasing trend (ST) and seasonality plus a decreasing trend (SD). These factors are related to many other previous works (Carlson et al. 1982; Omar and Bennell 2009). The demand functions created for each period are available in Table 4.

\subsection{Uncertainty in demand factor}

Uncertainty in demand is one of the most important factors in the supply chains' instability (Lee et al. 1997). In order to include it in the experiments, a normal random variation function centred on demand was added to each $\mathrm{PH}$. This proposal is based on the solution by Coronado-Hernández (2016) of applying a uniform random function, or on that of Carlson et al. (1982) of a normal and bimodal-normal demand pattern.

This normal random variation will take the total demand of each period $\mathrm{D}_{\mathrm{t}^{\prime}}$ as the standard deviation, and a coefficient of uncertainty, Coef. Incert., according to Eq. (1) will be done on each $\mathrm{PH}$, as identified by the index of ro. Only positive and integral demands are used.

$D_{t, r o}=\operatorname{Round}\left(\operatorname{Max}\left(0, D_{t^{\prime}}(1+\right.\right.$ Coef.Incert. $\times$ Normal_Box_Muller $\left.\left.[0,1])\right), 0\right) ; D_{t, r o} \in \mathbb{Z}^{+}$

$$
\begin{aligned}
& \text { Normal_Box_Muller }[0,1] \\
& \quad=\sqrt{-2 \ln a_{1}} \sin \left(2 \pi a_{2}\right) ; a_{1}, a_{2} \text { are uniform random; } a_{1}, a_{2}<1 ; a_{1}, a_{2} \geq 0
\end{aligned}
$$

$D_{t=1, r o}$ is the demand of the first period on the PH of $r o . D_{t=2-8, r o}$ are the demand forecast of the others seven periods on the $\mathrm{PH}$ of $r o$. $D_{t^{\prime}}$ is the total demand of each period of the LTPH from previous factor. Xie et al. (2003) highlighted, by field data, that variability can reach $40 \%$. "Normal_Box_Muller[0, 1]" gives the normal random values centred on zero with a standard deviation of one according to Eq. (3) (Lee et al. 2006), where $a_{1}$ and $a_{2}$ are two uniform random numbers. 


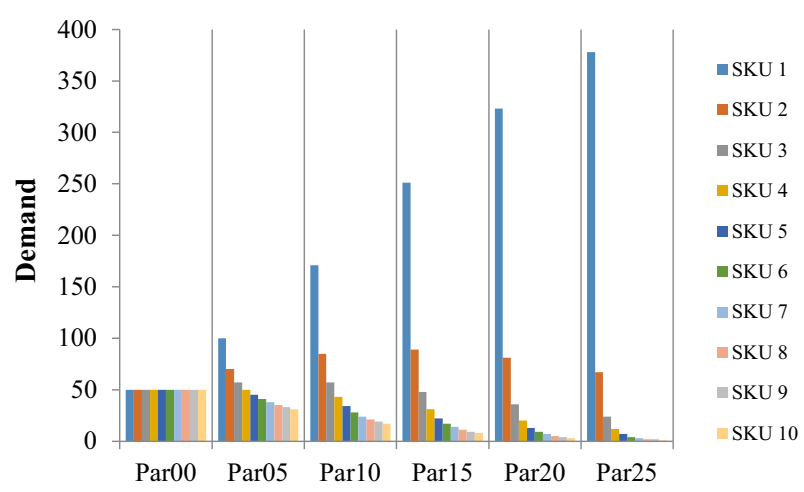

Fig. 4 Representation of demand distribution according to Zipf's law. Source: the Authors according to Newman (2004)

For clarity sake, the qualitative independent factor of demand uncertainty takes the CV00, CV10, CV20, CV30, CV40 and CV50 values as Coef.Invert. takes the 0\%, $10 \%, 20 \%, 30 \%, 40 \%$ and $50 \%$ values.

\subsection{Irregular demand distribution (Pareto) factor}

This factor collects the differences in demand among the 10 final products of each instance. It characterises that not all products have homogeneous demand, but an $\mathrm{ABC}$ of product demand can be applied. Zipf's law is used for this purpose (Newman 2005), where each product follows the demand distribution of Eq. (3), where $D i, t, r o$ is the demand of each final product $i$ during period $t$ and $\mathrm{PH} r o ; D_{t, r o}$ is the total demand of each period $t$ on PH $r o$ from previous factor. $\alpha$ takes the $0,0.5,1,1.5,2,2.5$ values, which define the alternatives of this factor. For clarity sake, the Pareto independent qualitative factor may take the Par00, Par05, Par10, Par15, Par20 and Par25 values, which are observed in Fig. 4.

$$
\mathrm{D}_{i, t, r o}=\mathrm{D}_{t, r o} i^{-\alpha}
$$

For Par00 $(\alpha=0)$, it can be seen that demand distribution is homogeneous and that as $\alpha$ increases, distribution is accentuated by increasing the difference between SKU 1 with the highest demand and SKU 10 with the lowest demand.

\subsection{Resources saturation factor}

In this factor, the effects of the available capacity limitation are analysed. The capacity limitation can be stated for production, procurement or transportation (Maheut and Garcia-Sabater 2011). The capacity limitation influences the effects produced by a variation in the $\mathrm{PH}$ and $\mathrm{FI}$ (Xie et al. 2003). This factor was not found in some previous test beds (Carlson et al. 1982; Coronado-Hernández 2016; DeYong and Cattani 2016; Prasad and Krishnaiah Chetty 2001; Stadtler 2000). Based on the available capacities 
Table 5 Parameters of instances. Source: Own elaboration

\begin{tabular}{|c|c|c|c|c|c|}
\hline Pareto & Demand & Uncertainty & BOM & Saturation & Instance \\
\hline $\begin{array}{l}\text { Par00, Par05, } \\
\text { Par10, } \\
\text { Par15, } \\
\text { Par20, } \\
\text { Par25 }\end{array}$ & $\begin{array}{c}\mathrm{CC}, \mathrm{TT}, \mathrm{SS}, \\
\text { ST, SD }\end{array}$ & $\begin{array}{l}\text { CV00, CV10, } \\
\text { CV20, CV3, } \\
\text { CV40, } \\
\text { CV50 }\end{array}$ & $\begin{array}{l}\mathrm{P} 1, \mathrm{P} 2, \mathrm{P} 3, \\
\text { P4, P5, P6 }\end{array}$ & $\begin{array}{l}\text { R00, R75, } \\
\text { R50, R30 }\end{array}$ & $\begin{array}{l}1,2,3,4,5,6 \\
7,8,9,10 \\
11,12\end{array}$ \\
\hline
\end{tabular}

for each resource set according to Coronado-Hernández (2016) of 2000 time units, it is reduced by different levels. The full capacity of 2000UT is assigned to R00, the reduction of $25 \%$ to $1500 \mathrm{UT}$ of the available capacity is assigned to R75, and so forth. The available capacities for each resource during each period (R1, R2, R3, R4, R5), Fig. 3, take the 2000 UT, 1500 UT, 1000 UT, 600 UT values. For clarity sake, the qualitative independent saturation factor takes the R00, R75, R50 and R30 values.

\subsection{Instance coding}

Twelve $^{1}$ instances of each combination between the independent factors were generated to have a statistically sufficiently representative one from each factor. The differences between these 12 instances lie in the values of the random parameters introduced into both demand noise and uncertainty. The summary of all the instances is found in Table 5. The coding of instances contained their used combination; e.g. with "Par00_CC_CV00_P1_R00_9" meaning Par00 the Pareto type, CC the demand type, $C V 0 O$ the type of uncertainty in demand, $P l$ the product structure type, $R 00$ the level of resources saturation and 9 being the number of the instance. The 51,840 instances are available on http://personales.upv.es/greriuso/TEST_BED_GMOP.rar. The file structure of the instance test bed is found in the "Appendix".

\section{Test bed characterisation}

To model the test bed, the GMOP formulation was used after considering possible penalties for non-compliance or delays in requested demand. The GMOP formulation is a representation of the batch size (multilevel, multisubprocess and multipostprocess, multistructure, multiperiod) problem with limited capacity. The list of the model's indices, parameters and variables is observed in Table 6. The function to be minimized is the objective of including the inventory holding cost, penalties for delay, the stroke setup cost and the stroke costs at each PH, as seen in Eqs. (4) with the restrictions of Eqs. (5)-(8).

The restrictions represented by Eqs. (5) are those of inventory and they connect logistics (stocks, delays and demand) with operations (product consumption and

\footnotetext{
${ }^{1}$ Twelve instances are carried out for each combination of factors, given the recommendation to perform between nine and fifteen, and that it is more important to validate the results than to increase the number of observations (Hair et al. 1999).
} 
Table 6 Indices, parameters and variables used in GMOP formulation. Source: based on Garcia-Sabater et al. (2013)

\begin{tabular}{ll}
\hline Indices & \\
$i$ & Index set of SKUs (including products, packaging and site) \\
$t$ & Index set of planning periods in each PH (t' refers to LTPH) \\
$r$ & Index set of resources \\
$k$ & Index set of strokes \\
$r o$ & Index set of PH \\
Parameters & \\
$D_{i, t, r o}$ & Demand of SKU $i$ for period $t$ on PH $r o$ \\
$H_{i, t}$ & Cost of storing a unit of SKU $i$ during period $t$ \\
$C O_{k, t}$ & Cost of stroke $k$ cost during period $t$ \\
$C S_{k, t}$ & Cost of the stroke $k$ setup during period $t$ \\
$C B_{i, t}$ & Cost of delay of SKU $i$ during period $t$ \\
$S O_{i, k}$ & Number of units of SKU $i$ that generates a stroke $k$ \\
$S I_{i, k}$ & Number of units of SKU $i$ that stroke $k$ consumes \\
$L T_{k}$ & Lead time of stroke $k$ \\
$K A P_{r, t}$ & Capacity availability of resource $r$ during period $t$ (in time units) \\
$M$ & A sufficiently large number \\
$T O_{k, r}$ & Capacity of resource $r$ required for performing one unit of stroke $k$ (in time units) \\
$T S_{k, r}$ & Capacity required of resource $r$ for stroke $k$ setup (in time units) \\
Variables & \\
$z k, t, r o$ & Amount of strokes $k$ to be performed during period $t$ on PH $r o$ \\
$\delta_{k, t, r o}$ & $=1$ if stroke $k$ is performed during period $t$ on PH $r o$ (0 otherwise) \\
$f_{i, t, r o}$ & Delay quantity of SKU $i$ during period $t$ on PH $r o$ \\
$x_{i, t, r o}$ & Stock level of SKU $i$ on hand at the end of period $t$ on PH $r o$ \\
$S K U S t o c k$ &
\end{tabular}

SKU Stock keeping unit, $P H$ planning horizon

creating new products). Equations (6) define the capacity limitations for resources. Equations (7) establish the setup requirements when these operations are carried out during period $t$ with stroke $k$ in $\mathrm{PH}$ ro. Finally, Eq. (8) establish variable domains.

$$
\min \sum_{t} \sum_{i}\left(H_{i, t} x_{i, t, r o}+C B_{i, t} f_{i, t, r o}\right)+\sum_{t} \sum_{k}\left(C S_{k, t} \delta_{k, t, r o}+C O_{k, t} z_{k, t, r o}\right) \forall \text { ro }
$$

$$
\begin{aligned}
x_{i, t, r o}= & x_{i, t-1, r o}-D_{i, t, r o}+f_{i, t, r o}-f_{i, t-1, r o} \\
& -\sum_{k}\left(S I_{i, k} z_{k, t, r o}\right)+\sum_{k}\left(S O_{i, k} z_{k, t-L T_{k}, r o}\right) \forall i, t, r o \\
& \sum_{k}\left(T S_{k, r} \delta_{k, t, r o}\right)+\sum_{k}\left(T O_{k, r} z_{k, t, r o}\right) \leq K A P_{r} \quad \forall r, t, r o
\end{aligned}
$$




$$
\begin{gathered}
z_{k, t, r o}-\mathrm{M} * \delta_{k, t, r o} \leq 0 \quad \forall k, t, \text { ro } \\
x_{i, t, r o} \geq 0 ; f_{i, t, r o} \geq 0, \forall i, t, r o ; z_{k, t, r o} \in \mathbb{Z}^{+} ; \delta_{k, t, r o} \in\{0,1\} \quad \forall k, t, r o
\end{gathered}
$$

\section{Dependent variable elements of the test bed resolutions}

In this section, different measurable elements are shown that allow comparisons of the planning proposals of the operations that can be obtained for each of instances of the test bed presented. In the operations planning model, the objective is to reduce total costs based on decision variables. On each $\mathrm{PH}$, a new planning proposal is made that updates the previous proposal. These plans define the operations to be carried out during each period to meet the objective set out in the model. The measurable elements proposed below allow comparisons of the different planning proposals to be obtained in relation to the independent variables raised in the instance test bed based on costs and meeting demand:

1. Regarding the cost of the planning proposal for these instances:

- The total cost of the planning proposal for the periods under study, 52 periods in these instances, is seen in Eq. (9), with the values for the decision variables proposed for the GMOP model in Eqs. (4)-(8). Total costs refer to the different costs included in the objective function proposed by the model. Instances allow the inclusion of the costs of planned operations, setup, storage and penalties for delays in meeting demand in the objective function for FI.

$$
T C R=\sum_{r o=13}^{64}\left(\sum_{t=1}^{F I}\left(\sum_{i}\left(H_{i, t} x_{i, t, r o}^{\prime}+C B_{i, t} f_{i, t, r o}^{\prime}\right)+\sum_{k}\left(C S_{k, t} \delta_{k, t, r o}^{\prime}+C O_{k, t} z_{k, t, r o}^{\prime}\right)\right)\right)
$$

$\mathrm{x}^{\prime}, \mathrm{f}^{\prime}, \delta^{\prime}, \mathrm{z}^{\prime}$ are the values for the decision variables proposed for the GMOP model with Eqs. (4)-(8).

2. Regarding the service level, the level of unmet demand is measured according to the demand requested during the 52 periods with Eq. (10), based on Y1ldırım et al. (2005). In this test bed, only final products have demand. $f_{i, t, r o}$ is the amount of SKU $i$ in the delay during period $t$ on PH ro and $D_{k, t, r o}$ is the demand of SKU $i$, during period $t$, on $\mathrm{PH}$ ro. The executed period is only in $t$ and equals one as RP and FI are chosen as one.

$$
N S R=\frac{\sum_{r o=13}^{64}\left(1-\frac{\sum_{t=1}^{F I} \sum_{i} f_{i, t, r o}}{\sum_{t=1}^{F I} \sum_{i} D_{i, t, r o}}\right)}{52}
$$

\section{Solution for instances}

In order to find the best solution for the 51,840 instances of the test bed presented according to the described model, the GUROBI ${ }^{\circledR}$ commercial program was executed 
in the Rigel cluster. This cluster is based on the grid architecture and a multicore PC of the Polytechnic University of Valéncia. It includes 72 Fujitsu BX920S3 nodes installed in BX900S2 chassis. Each node includes 2 Intel Xeon E5-2450 processors (8 cores/16 threads, $2.1-2.5 \mathrm{GHz}$ ) and $64 \mathrm{~GB}$ of DDR3 RAM. Nodes are linked by $2 \times 10$ GB Ethernet interfaces. The cluster runs a CentOS 6 operating system and Sun Grid Engine manages its load. The multi-core PC runs a CentOS 6.4 operating system with an Intel Core i5-4670 processor (4 cores/4 threads, $3.4 \mathrm{GHz}$ ), with $8 \mathrm{~GB}$ of DDR3 RAM (ASIC 2018) and the GUROBI ${ }^{\circledR}$ solution search programme 7.0.2 64 bits for Linux.

Instances were resolved with the allowable gap specifications of below $1 \%$ (GRB.DoubleParam.MIPGap $=0.01$ ). The calculations for each instance are performed in a single core of the server processor (GRB.IntParam.Threads $=1$ ). The calculation limit of each horizon on which it was planned was $3000 \mathrm{~s}$ (GRB.DoubleParam.TimeLimit $=3000$ ).

The representation of the measurement elements in relation to the independent factors was done with the non-parametric test of median of Mood (Pérez 2002). It is calculated with the Statgraphics Centurion $\mathrm{XVII}^{\circledR}$ program. This test allows the effects caused by each factor to be analysed. It also evaluates if the null hypothesis that the medians of the different levels or options of each factor are equal. This test is performed by counting the number of observations in each sample on each side of the global median, and that the $P$ value of the Chi square test is less than 0.05 . Therefore, the median levels or options of each factor significantly differ at the $95 \%$ confidence level. The 95\% confidence intervals for medians are also included based on the order statistics of each factor (Pérez 2002).

\subsection{Analysis of the distribution of the total costs in the 52 periods of the obtained planning proposals}

The effects of the different factors and their levels or options on the total costs are analysed, which is the sum of the costs of the periods run during the eight planning periods on the $52 \mathrm{PH}$ in which they were selected. Equation (9) was used.

Figure 5 shows the behaviour of the different product structure types in relation to the total costs. It is worth nothing that type product structure $P 6$, with an alternative process had the lowest total costs. Product structure $P 1$ come close to product structure $P 6$. It is also observed that product structure $P 5$ generated the highest total costs compared to the other structures. Product structure $P 5$ is the structure with the highest levels of subproducts.

Figure 6 shows the influence of the demand type in relation to the total costs. The pattern of increasing seasonal demand $S T$ had the highest costs. The decreasing seasonal demand type $S D$ was that which generated the lowest total costs in the different instances, below the constant demand $C C$. Instances were solved by seeking to minimize the objective function of the total costs for each $\mathrm{PH}$. Therefore in a decreasing demand type, uncertainties were offset by decreasing stocks. The costs for delays were more important than the setup or storage cost. Therefore, the total costs were lower when demand seasonally decreased. 


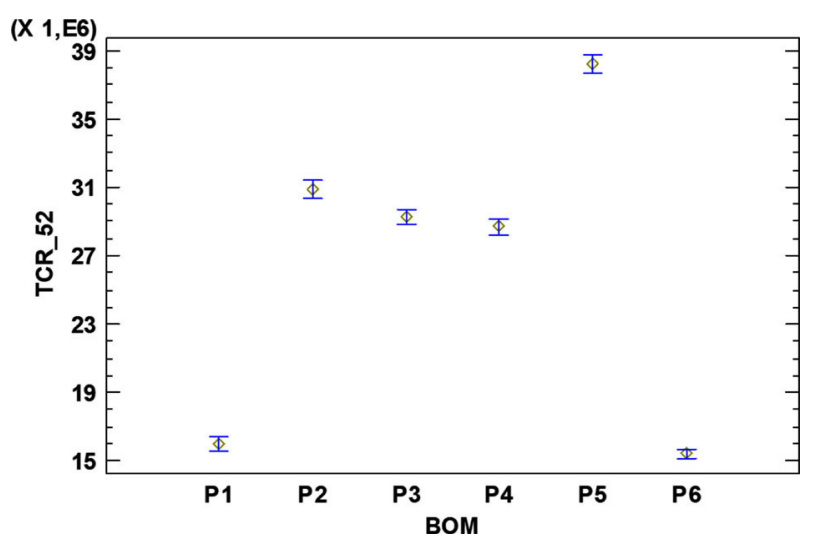

Fig. 5 Graph of the medians of the product type factor in relation to the total costs with $95 \%$ confidence intervals. TCR_52 total costs in the 52 analysis periods, BOM type of product. Source: the Authors using Statgraphics Centurion XVII ${ }^{\circledR}$

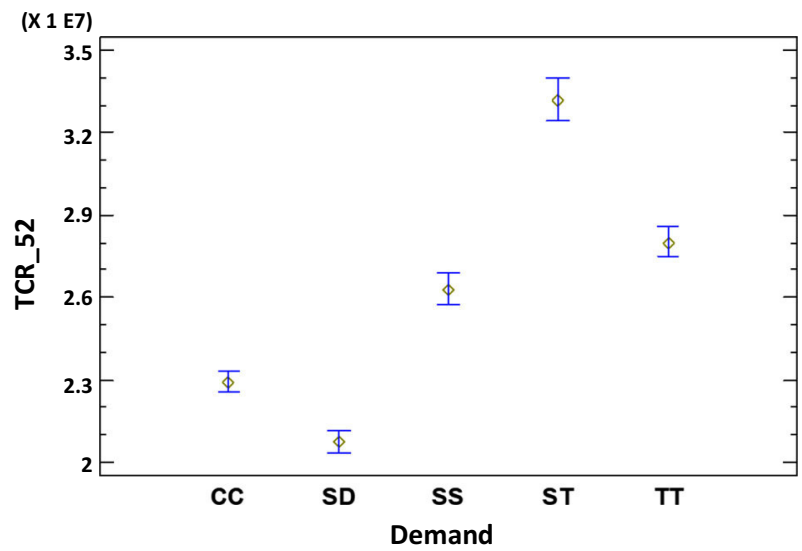

Fig. 6 Graph of the medians of the demand type factor in relation to the total costs with $95 \%$ confidence intervals. TCR_52 total costs in the 52 analysis periods, Demand type. Source: the Authors using Statgraphics Centurion XVII ${ }^{\circledR}$

Figure 7 shows the specific behaviour of the influence of the irregular demand distribution factor (Pareto) on the total costs. Costs increased as irregularity rose, although its different distributions had costs related to the $95 \%$ confidence intervals. Significant differences appeared between the distribution of the results of two factor levels. For example, between ParOO and ParlO significant statistical differences appeared with $95 \%$ confidence intervals, but not between ParOO and Par05. The variation in the total costs went unnoticed when comparing between the last factor levels, and between Par20 in relation to Par25. The variations in the total costs due to the irregular demand distribution were not as marked as the variations in costs that appeared between different product types. Figure 5 compared to Fig. 7 depicts how variations between product types present bigger differences than variations between irregular demand distribution types. 


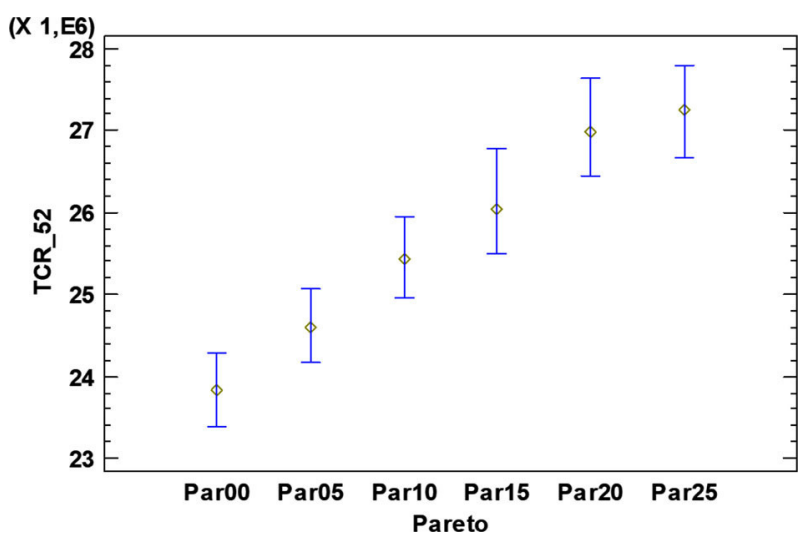

Fig. 7 Graph of the median of the Pareto factor in relation to the total costs with $95 \%$ confidence intervals. TCR_52 total costs in the 52 analysis periods, Pareto factor of irregular demand distribution. Source: the Authors using Statgraphics Centurion XVII ${ }^{\circledR}$

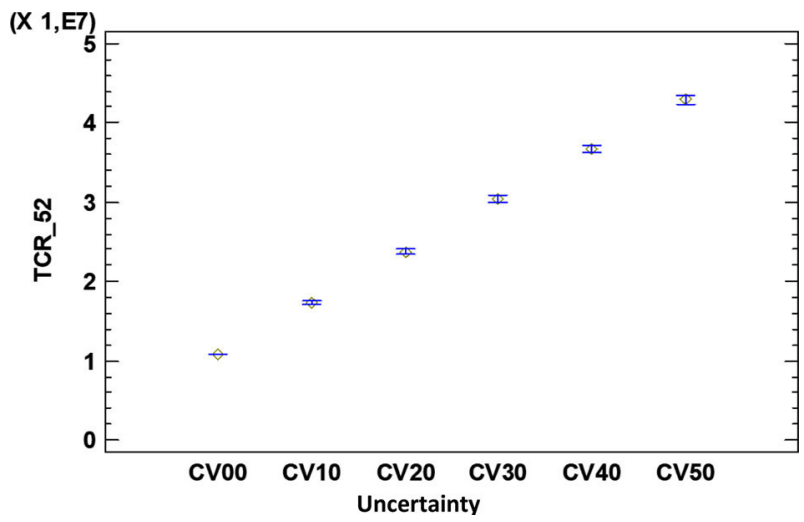

Fig. 8 Graph of the medians of the uncertainty factor in relation to the total costs with $95 \%$ confidence intervals. TCR_52 total costs in the 52 analysis periods, the Uncertainty factor of uncertainty in demand. Source: the Authors using Statgraphics Centurion XVII ${ }^{\circledR}$

The interaction of demand uncertainty in the total costs is shown in Fig. 8. It was concluded that increased uncertainty brought about a clear increase in total costs. The uncertainty factor presented the largest differences in the total costs. Uncertainty had a stronger impact on the delay costs, which were more important than the setup cost or the storage cost.

In Fig. 9, the influence of the saturation of the available capacity of all resources can be evaluated. The $30 \%$ levels of available capacity, R30, appeared when the highest total costs occurred, mainly for penalties for delays in demand requirements. Lack of available resources in $R 30$ generated the highest total costs compared to other factors like demand type, irregular demand distribution, product type or uncertainty. Only the $50 \%$ levels of uncertainty came close to the medians of the total costs generated by lack of available resources. Lack of available resources meant that it was impossible to meet demand requirements, which resulted in high cost due to delay. 


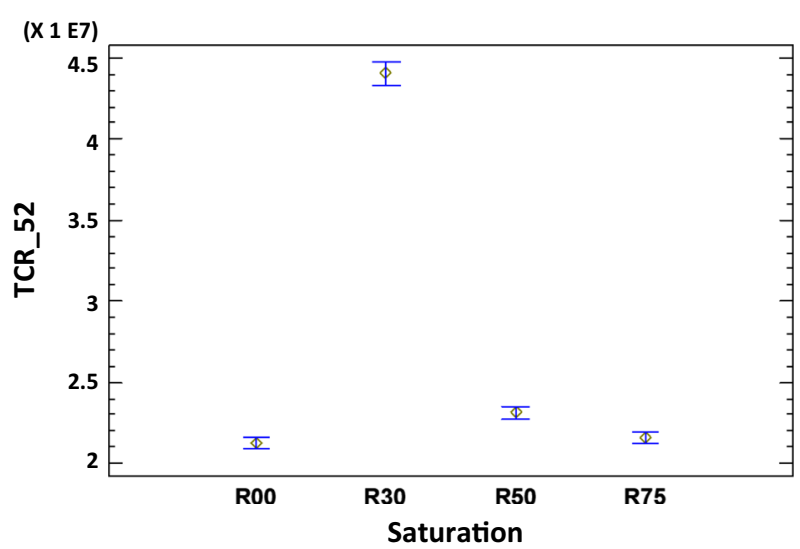

Fig. 9 Graph of the medians of the resources saturation factor in relation to total costs with $95 \%$ confidence intervals. TCR_52 total costs in the 52 analysis periods, Saturation factor of resource saturation. Source: the Authors using Statgraphics Centurion XVII ${ }^{\circledR}$

No significant variations appeared between the $100 \%$ capacity provision, $R 00$ and $75 \%$ availability, $R 75$. This $25 \%$ reduction still left sufficient available capacity levels to meet the requested demands. Only with a 50\% reduction, $R 50$, did statistically significant increases appear in the total costs within $95 \%$ confidence. When the reduction was $70 \%, R 30$, it significantly affected the total costs, mainly the cost of delay, which was relatively more important than the production, setup or storage costs.

In the Par00_ST_CV10_P1_R30_1 instance, the total costs due to the penalty for delays were $90 \%$ versus $10 \%$ for the production, setup or storage costs. In the Par00_ST_CV10_P1_R00_1 instance, there were 23\% penalties for delay cost versus $69 \%$ for set up. Therefore, lack of resources, $R 30$, implied an increase in costs due to delays compared to the setup costs.

\subsection{Analysis of the distribution of the service level in the 52 periods of the obtained planning proposals}

This section presents the service level behaviour due to the different effects of the studied factors. To measure the service level, in this section Eq. (10) was used, which evaluated the level of final unmet demand based on the demand requested in the 52 studied periods. From instance Par00_ST_CV10_P1_ROO_l in Fig. 10, the relative importance of the different elements of the objective function can be seen. It highlights the predominant weight of delay costs and setup costs, and the generated service levels are over $92 \%$.

Figure 11 shows how the complexity of the product affected the service level. The worst service levels are highlighted with product type $P 5$ compared to the structures with fewer levels like $P l$ or structures with alternative operations $P 6$. Product structure $P 6$ approaches a service level that comes close to one and the lower total costs. Systems are able to adapt better to the demand requirements at a lower cost in this product structure $P 6$. Product structure $P 5$ requires more forecast periods to programme its 


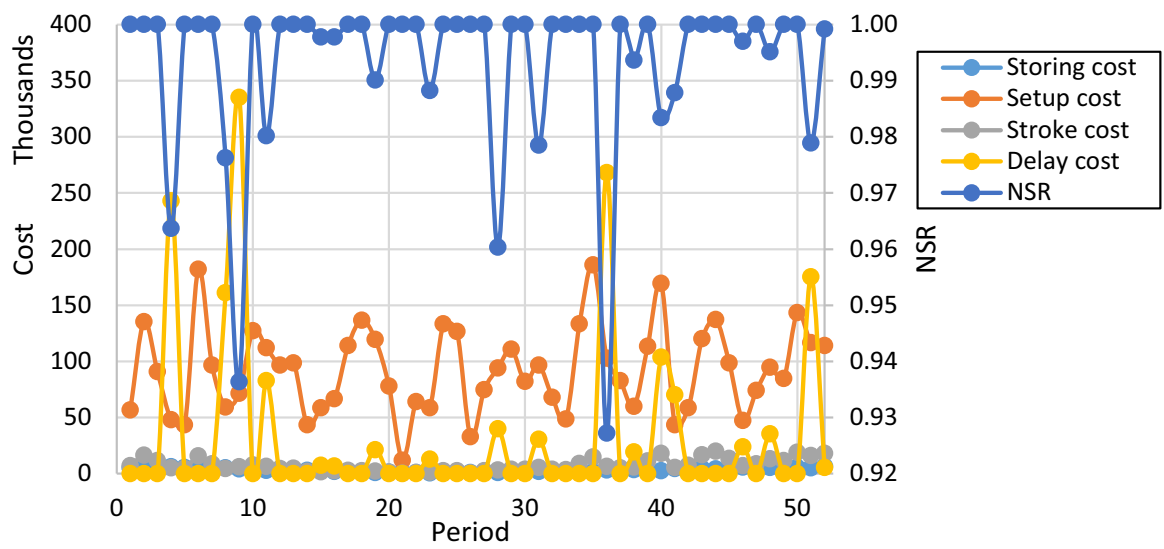

Fig. 10 Decomposition of the costs and service level of Par00_ST_CV10_P1_R00_1. Storing and inventory holding cost during each period. The NSR average service level of the 10 final products during this period. Source: the Authors

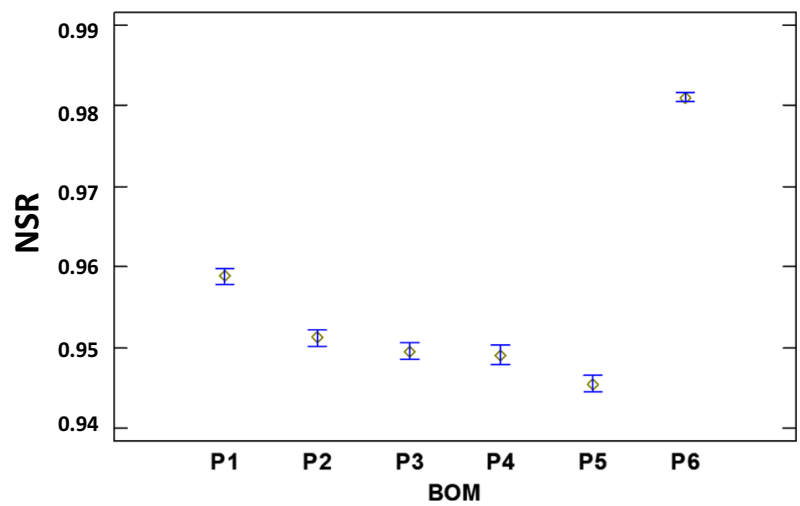

Fig. 11 Graph of the medians of the product type factor in relation to NSR with $95 \%$ confidence intervals. NSR service level in the 52 analysis periods, the BOM product type. Source: the Authors with Statgraphics Centurion XVII ${ }^{\circledR}$

operations. It offers greater stability as to when to start or not, and variations in the demand for more periods need to be withstood, which results in higher costs and worse service levels.

Figure 12 shows that the irregular demand distribution factor barely influences the service level, with worse service levels at high factor levels.

Figure 13 shows how uncertainty significantly affects the service level. When uncertainty in demand is lacking, the service level is better. Yet as uncertainty levels increase, service levels become worse following a constant proportionality curve, as with the total cost.

Figure 14 shows how the resources saturation factor affects the service level. A statistically significant difference is observed when only $30 \%, R 30$, of the capacity of all resources is available. An equivalent distribution of the effects of the available 


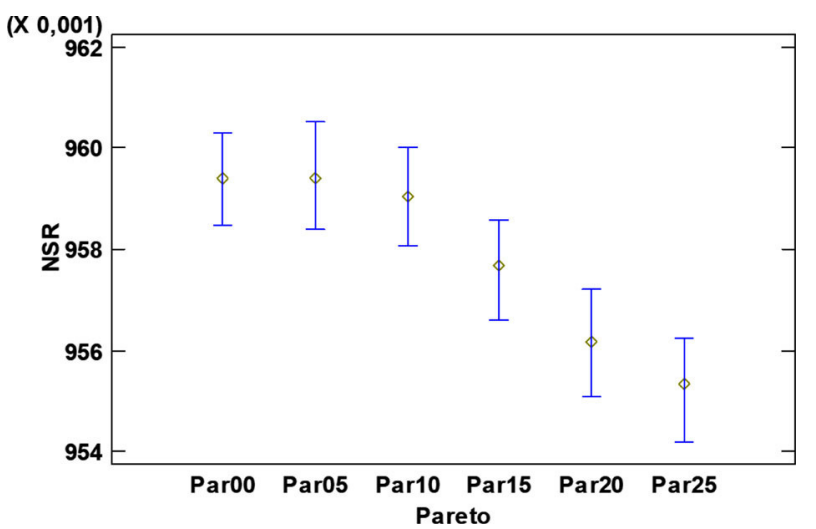

Fig. 12 Graph of the medians of the Pareto factor in relation to NSR with $95 \%$ confidence intervals. NSR service level in the 52 analysis periods, the Pareto product type. Source: the Authors with the Statgraphics Centurion XVII ${ }^{\circledR}$

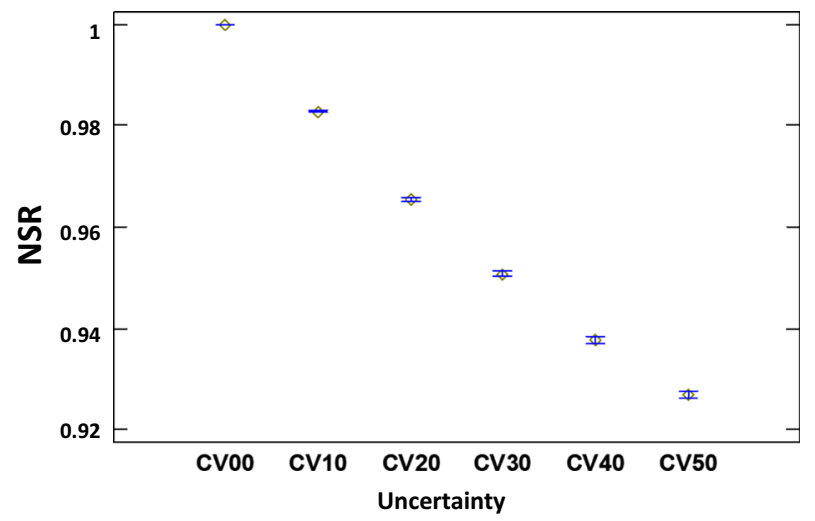

Fig. 13 Graph of the medians of the uncertainty factor in relation to NSR with $95 \%$ confidence intervals. NSR total service level in the 52 analysis periods, the Uncertainty factor of uncertainty in demand. Source: the Authors with Statgraphics Centurion XVII ${ }^{\circledR}$

capacity factor is found in the total costs (see Fig. 9). No statistically significant differences appear in the first available capacity factor levels, $R 00$ and $R 75$, in both the total costs and service levels.

Regarding demand types, Fig. 15 show how the service level worsens with seasonal demand (SD), (SS) and (ST) and also with increasing demands (TT). It should be noted that the seasonal with decreasing demand (SD) has a lower median total cost than constant demand (CC), Fig. 6, but has a worse service level than (CC); Fig. 14. Less demand implies a reduction in the total cost, but seasonal demand implies a worse service level. Constant demand allows a better service level, even if it has a higher total cost than seasonal decreasing demand. 


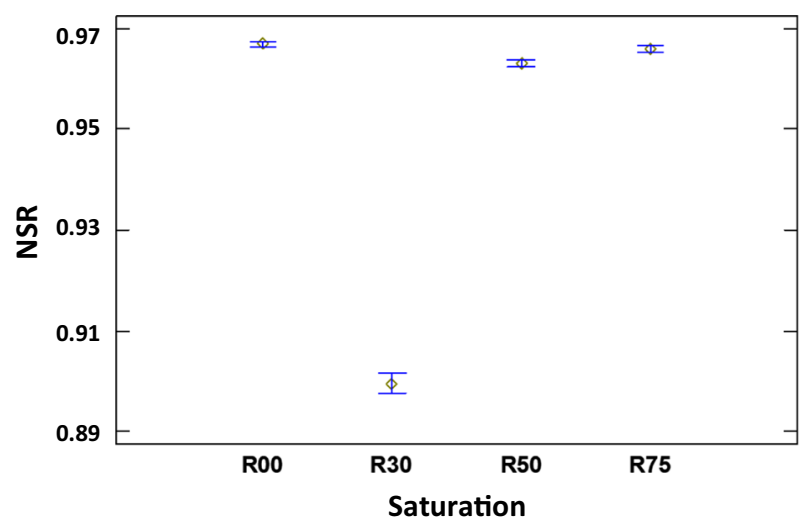

Fig. 14 Graph of the medians of the resources saturation factor in relation to NSR with $95 \%$ confidence intervals. NSR total service level in the 52 analysis periods, the Saturation factor of resource saturation. Source: the Authors with Statgraphics Centurion XVII ${ }^{\circledR}$

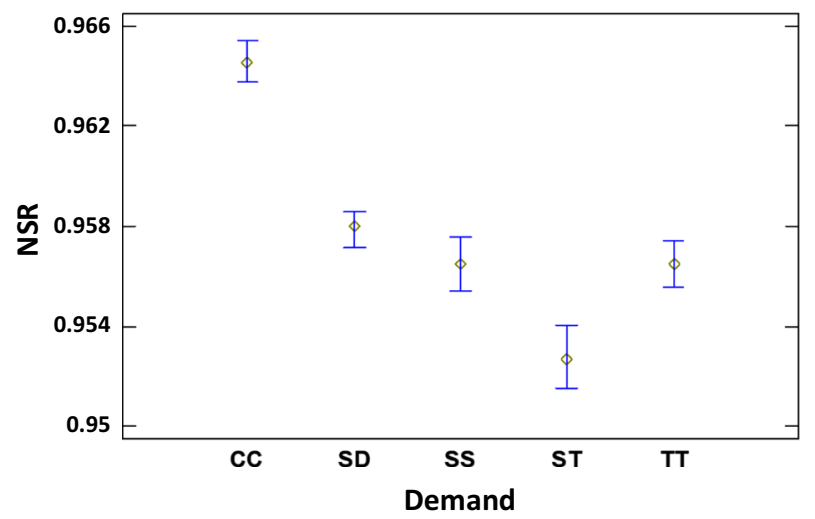

Fig. 15 Graph of the medians of the demand type factor in relation to NSR with $95 \%$ confidence intervals. $N S R$ service level in the 52 analysis periods, Demand type of demand. Source: the Authors with Statgraphics Centurion XVII ${ }^{\circledR}$

\section{Conclusions}

Planning through RH is common in industry (Sahin et al. 2013), and also in academic research as a tool to solve major mathematical programming problems as such it simplifies and reduces them to affordable sizes to the available computational capacities. The availability of a large test bed will allow future research given that the behaviour of this heuristic in stochastic situations has not yet been developed (DeYong and Cattani 2016; Sahin et al. 2013).

This repertoire of instances allowed the analysis of the behaviour of the RH heuristic in relation to the five introduced independent variables and the $\mathrm{RH}$ elements (PH, FI, RP, lot-sizing rule) or forecast tools (Holt-Winters, Theta, ARIMA, etc.). The different situations allow their consequences on total costs and service level to be measured. 
The consequences of the analysed independent factors were evaluated by measuring the total costs and the service level of the 52 periods under study. The commercial program Statgraphics Centurion XVII $\odot$ allowed the different results to be represented. It was segregated by factors to visualise the different consequences of the different levels.

From this analysis the following could be concluded:

- In environments with seasonal and growing demand patterns, the highest total costs are presented along with the worst service levels.

- The product type with more levels, type $P 5$, has the highest total costs and worst service levels.

- The structures of products with lower levels, type $P 1$, are carried out during a single period with the operations of final products, or with alternatives, e.g. type $P 6$, with better service levels and lower total costs. However, these product structures may sustain planning modifications among PH that can be seen in nervousness. Product structures $P 6$ allow a service level close to the unit with lower total costs to be approached.

- Uncertainty in demand is directly related and constantly proportional to the increase in total costs and the worst service levels. The total cost increases with the higher penalties for service delays. Delays are due to lack of available stocks of subproducts or the insufficient capacity to meet these changes in demand. The higher uncertainty in demand levels with $C V 50$, which has the lowest capacity with $R 30$, generates the highest total cost levels and the worst service level.

- A more irregular distribution of demand among products generates higher total costs and worse service levels, and uncertainty of demand concentrates in one product.

- The reduction of the available capacity of resources, saturation factor, generates more delays due to the insufficient capacity to meet demands, which increased total costs. In addition, this saturation leads to a worse service level, which increases with higher uncertainty, and when demand patterns are seasonal and with growing demand.

- The lower levels of reducing available capacity, such as $R 00$ and $R 75$, saturation factor, do not present significant differences in either the total costs or service level, but may present differences in relation to nervousness. The reduction in the available capacity of resources can be compensated with more marked changes in the amounts of strokes to be processed, but they maintain the total cost levels and service levels. - The decreasing seasonal demand type has a lower total cost than constant demand, but a worse service level given its seasonal demand.

The bed test allows the analysis of how different demand patterns influence the costs of operations planning and service level. For example, the combination of factors influences planning proposals because the decreasing trend seasonal demand pattern can be influenced unequally by the Pareto factor at the service level.

Future research should add other elements, independent or dependent variables for operation planning. Other types of products can be added as co-products. Other forms of mathematical models for the uncertainty factor can be investigated as steps and skews. Dependent variables like instability should be evaluated, especially with alternatives operations. The incidence of product complexity or operations alternatives 
in the unequal form of nervousness as type I or in type II at different levels of available saturation or uncertainty in demand should be evaluated.

\section{Appendix: File structure of the instance test bed}

Instances are created in text files with extension.csv. Each field in the file is separated by a semicolon or a line break.

Instances present data according to a uniform structure of:

- The description of the parameters selected for the instance is between lines 1-6 of each file. An example is shown below:

- Pareto;Par00.

- Tipo_demanda;ST.

- Incertidumbre;CV10.

- BOM;P1.

- Saturacion;R00.

- The characteristics and calculation parameters proposed for the instance are between lines 7 and 16 of each file. An example is shown below:

- Productos_padre;10.

- Productos;50.

- Periodos;8

- Rodantes;52.

- RodantesPrev;12.

- Recursos;5

- Strokes;50.

- M;50,000.

- Gap_Gurobi/100,000b;1000.

- Lim_timp_Gurobi;3000.

- The expected demand calculated for all the periods and final products is between lines $17-27$ of each file.

- The demands for all the 10 final products in all eight periods on each $\mathrm{PH}$ are between lines 28 and 731 of each file. The first period is confirmed demand and the other periods are the demand forecasts. A graph representation is seen in Fig. 16 of Par00_ST_CV10_P5_R30_5.

- The initial stock of each product of the instance are between lines 732 and 733 of each file.

- The storage costs for each product and in all eight periods are between lines 734 and 742 of each file.

- The setup costs of each stroke in all eight periods are between lines 743 and 751 of each file.

- The costs of each stroke in all eight periods are between lines 752 and 760 of each file.

- The available capacity of each resources is between lines 761 and 762 of each file. 


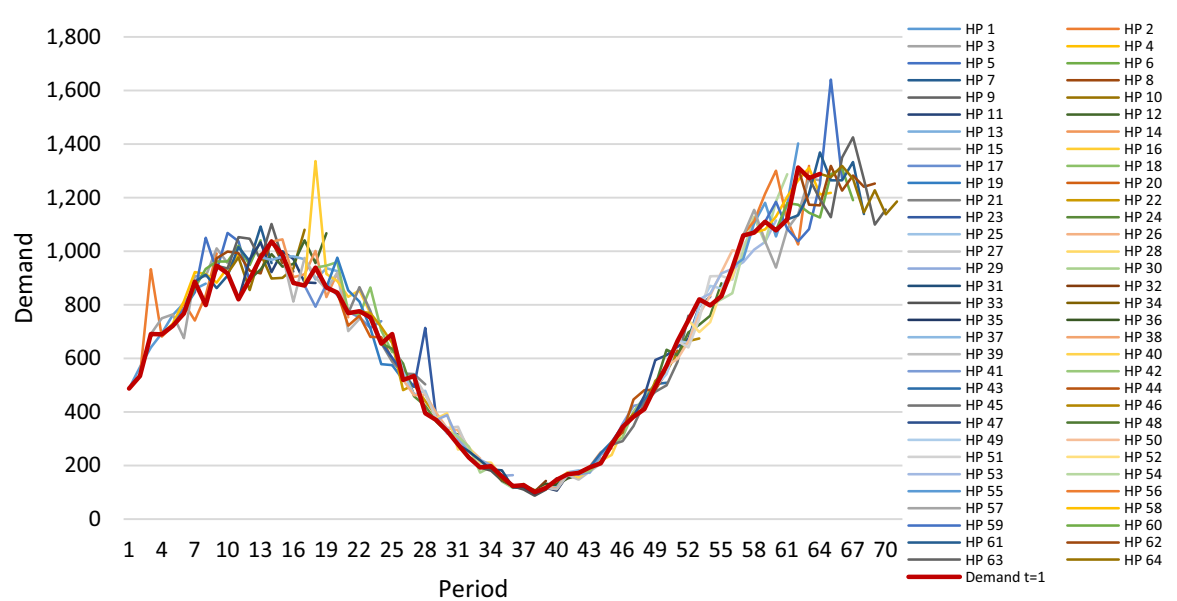

Fig. 16 Demands of the 71 periods of the 64 PH of ParO0_ST_CV10_P5_R30_5. Source: the Authors

- Delivery times or those necessary to perform each operation are between lines 763 and 764 of each file.

- The matrix of products resulting from each strokes is between lines 765 and 815 of each file.

- The matrix of products consumed by each strokes is between lines 816 and 866 of each file.

- The matrix of the resources required for the setup of each strokes is between the lines 867 and 872 of each file.

- The matrix of the resources required to perform each strokes is between lines 873 and 878 of each file.

- The matrix of the cost of delay of each products during each period is between lines 879 and 887 of each file.

\section{References}

Araujo SA, Arenales MN, Clark A (2007) Joint rolling-horizon scheduling of materials processing and lot-sizing with sequence-dependent setups. J Heuristics 13(4):337-358. https://doi.org/10.1007/s107 32-007-9011-9

ASIC (2018) Clúster de cálculo: Rigel. http://www.upv.es/entidades/ASIC/catalogo/857893normalc.html. Accessed date 22 July 2018

Baker KR (1977) An experimental study of the effectiveness of rolling schedules in production planning. Decis Sci 8(1):19-27. https://doi.org/10.1111/j.1540-5915.1977.tb01065.x

Barrett RT, LaForge RL (1991) A study of replanning frequencies in a material requirements planning system. Comput Oper Res 18(6):569-578. https://doi.org/10.1016/0305-0548(91)90062-V

Behnamian J, Fatemi Ghomi SMT (2014) A survey of multi-factory scheduling. J Intell Manuf 27:1-19. https://doi.org/10.1007/s10845-014-0890-y

Billington PJ, McClain JO, Thomas LJ (1983) Mathematical programming approaches to capacityconstrained MRP systems: review, formulation and problem reduction. Manag Sci 29(10):1126-1141. https://doi.org/10.1287/mnsc.29.10.1126

Blackburn JD, Millen RA (1980) Heuristic lot-sizing performance in a rolling-schedule environment. Decis Sci 11(4):691-701. https://doi.org/10.1111/j.1540-5915.1980.tb01170.x 
Cao Y (2015) Long-distance procurement planning in global sourcing. Ecole Centrale Paris. https://tel. archives-ouvertes.fr/tel-01154871/

Carlson RC, Beckman SL, Kropp DH (1982) The effectiveness o extending the horizon in rolling production scheduling. Decis Sci 13(1):129-146. https://doi.org/10.1111/j.1540-5915.1982.tb00136.x

Chand S, Hsu VN, Sethi S (2002) Forecast, solution, and rolling horizons in operations management problems: a classified bibliography. Manuf Serv Oper Manag 4(1):25-43. https://doi.org/10.1287/ msom.4.1.25.287

Coronado-Hernández JR (2016) Análisis del efecto de algunos factores de complejidad e incertidumbre en el rendimiento de las Cadenas de Suministro. Propuesta de una herramienta de valoración basada en simulación. Universitat Politècnica de València, Valencia (Spain). https://doi.org/10.4995/Thesis/102 $51 / 61467$

de Sampaio RJB, Wollmann RRG, Vieira PFG (2017) A flexible production planning for rolling-horizons. Int J Prod Econ 190:31-36. https://doi.org/10.1016/j.ijpe.2017.01.003

DeYong GD, Cattani KD (2016) Fenced in? Stochastic and deterministic planning models in a time-fenced, rolling-horizon scheduling system. Eur J Oper Res 251(1):85-95. https://doi.org/10.1016/j.ejor.2015 11.006

Federgruen A, Tzur M (1994) Minimal forecast horizons and a new planning procedure for the general dynamic lot sizing model: nervousness revisited. Oper Res 42(3):456-468. https://doi.org/10.1287/ opre.42.3.456

Fisher ML, Ramdas K, Zheng YS (2001) Ending inventory valuation in multiperiod production scheduling. Manag Sci 47(5):679-692. https://doi.org/10.1287/mnsc.47.5.679.10485

Garcia-Sabater JP, Maheut J, Garcia-Sabater JJ (2009. A capacitated material requirements planning model considering delivery constraints: a case study from the automotive industry. In: 2009 international conference on computers and industrial engineering, IEEE, pp 378-383. https://doi.org/10.1109/ICCIE. 2009.5223806

Garcia-Sabater JP, Maheut J, Garcia-Sabater JJ (2012) A two-stage sequential planning scheme for integrated operations planning and scheduling system using MILP: the case of an engine assembler. Flex Serv Manuf J 24(2):171-209. https://doi.org/10.1007/s10696-011-9126-Z

Garcia-Sabater JP, Maheut J, Marin-Garcia JA (2013) A new formulation technique to model materials and operations planning: the generic materials and operations planning (GMOP) problem. Eur J Ind Eng 7(2):119. https://doi.org/10.1504/EJIE.2013.052572

Hair JF, Prentice E, Cano D (1999) Análisis multivariante. Prentice-Hall, Upper Saddle River

Hozak K, Hill JA (2009) Issues and opportunities regarding replanning and rescheduling frequencies. Int J Prod Res 47(18):4955-4970. https://doi.org/10.1080/00207540802047106

Hsu CH, Yang HC (2017) Real-time near-optimal scheduling with rolling horizon for automatic manufacturing cell. IEEE Access 5:3369-3375. https://doi.org/10.1109/ACCESS.2016.2616366

Jans R (2009) Solving lot-sizing problems on parallel identical machines using symmetry-breaking constraints. Inf J Comput 21(1):123-136. https://doi.org/10.1287/ijoc.1080.0283

Karimi B, Fatemi Ghomi SMT, Wilson JM (2003) The capacitated lot sizing problem: a review of models and algorithms. Omega 31(5):365-378. https://doi.org/10.1016/S0305-0483(03)00059-8

Kimms A (1997) Multi-level lot sizing and scheduling, vol 53. Physica-Verlag, Heidelberg. https://doi.org/ 10.1007/978-3-642-50162-3

Kleindorfer P, Kunreuther H (1978) Stochastic horizons for the aggregate planning problem. Manag Sci 24(5):485-497. https://doi.org/10.1287/mnsc.24.5.485

Kumar BK, Nagaraju D, Narayanan S (2016) Supply chain coordination models: a literature review. Indian J Sci Technol. https://doi.org/10.17485/ijst/2016/v9i38/86938

Lalami I, Frein Y, Gayon JP (2017) Production planning in automotive powertrain plants: a case study. Int J Prod Res 55(18):5378-5393. https://doi.org/10.1080/00207543.2017.1315192

Lee HL, Padmanabhan V, Whang S (1997) The bullwhip effect in supply chains 1. Sloan Manag Rev Assoc 38(3):93-102. https://doi.org/10.1287/mnsc.43.4.546

Lee DU, Villasenor JD, Luk W, Leong PHW (2006) A hardware Gaussian noise generator using the boxmuller method and its error analysis. IEEE Trans Comput 55(6):659-671. https://doi.org/10.1109/TC. 2006.81

Lv Y, Zhang J, Qin W (2017) A genetic regulatory network-based method for dynamic hybrid flow shop scheduling with uncertain processing times. Appl Sci 7(1):23. https://doi.org/10.3390/app7010023 
Maheut J (2013) Modelos y Algoritmos Basados en el Concepto Stroke para la Planificación y Programación de Operaciones con Alternativas en Redes de Suministro. Universitat Politècnica de València, Valencia (Spain). https://doi.org/10.4995/Thesis/10251/29290

Maheut J, Garcia-Sabater JP (2011) La matriz de operaciones y materiales y la matriz de operaciones y recursos, un nuevo enfoque para resolver el problema GMOP basado en el concepto del stroke. Direccion y Organizacion 45:46-57

Maheut J, Garcia-sabater JP, Mula J (2012) A supply chain operations lot-sizing and scheduling model with alternative operations. In: Sethi SP, Bogataj M, Ros-McDonnell L (eds) Industrial engineering: innovative networks. Springer, London, pp 309-316. https://doi.org/10.1007/978-1-4471-2321-7

Meindl B, Templ M (2012) Analysis of commercial and free and open source solvers for linear optimization problems. Common Tools and Harmonized Methodologies for SDC in the ESS, pp 1-13. http://neon. vb.cbs.nl/cascprivate/..\%5Ccasc\%5CESSNet2\%5Cdeliverable_solverstudy.pdf

Meyr H (2002) Simultaneous lotsizing and scheduling on parallel machines. Eur J Oper Res 139(2):277-292. https://doi.org/10.1016/S0377-2217(01)00373-3

Narayanan A, Robinson P (2010) Evaluation of joint replenishment lot-sizing procedures in rolling horizon planning systems. Int J Prod Econ 127(1):85-94. https://doi.org/10.1016/j.ijpe.2010.04.038

Nedaei H, Mahlooji H (2014) Joint multi-objective master production scheduling and rolling horizon policy analysis in make-to-order supply chains. Int J Prod Res 52(9):2767-2787. https://doi.org/10.1080/00 207543.2014.884732

Newman M (2005) Power laws, Pareto distributions and Zipf's law. Contemp Phys 46(5):323-351. https:// doi.org/10.1080/00107510500052444

Omar MK, Bennell JA (2009) Revising the master production schedule in a HPP framework context. Int J Prod Res 47(20):5857-5878. https://doi.org/10.1080/00207540802130803

Pérez C (2002) Estadística práctica con Statgraphics ${ }^{\circledR}$. PEARSON EDUCACIÓN, S. A, Madrid

Poler R, Mula J (2011) Forecasting model selection through out-of-sample rolling horizon weighted errors. Expert Syst Appl 38(12):14778-14785. https://doi.org/10.1016/j.eswa.2011.05.072

Prasad PSS, Krishnaiah Chetty OV (2001) Multilevel lot sizing with a genetic algorithm under fixed and rolling horizons. Int J Adv Manuf Technol 18(7):520-527. https://doi.org/10.1007/s0017010180520

Rafiei R, Gaudreault J, Bouchard M, Santa-Eulalia L (2012) A reactive planning approach for demand-driven wood remanufacturing industry: a real-scale application, vol 71. CIRRELT, Montreal

Rafiei R, Nourelfath M, Gaudreault J, Santa-Eulalia LA, Bouchard M (2014) A periodic re-planning approach for demand-driven wood remanufacturing industry: a real-scale application. Int J Prod Res 52(14):4198-4215. https://doi.org/10.1080/00207543.2013.869631

Ramezanian R, Fallah Sanami S, Shafiei Nikabadi M (2017) A simultaneous planning of production and scheduling operations in flexible flow shops: case study of tile industry. Int J Adv Manuf Technol 88(9-12):2389-2403. https://doi.org/10.1007/s00170-016-8955-z

Rodriguez MA, Montagna JM, Vecchietti A, Corsano G (2017) Generalized disjunctive programming model for the multi-period production planning optimization: an application in a polyurethane foam manufacturing plant. Comput Chem Eng 103:69-80. https://doi.org/10.1016/j.compchemeng.2017.0 3.006

Sahin F, Narayanan A, Robinson EP (2013) Rolling horizon planning in supply chains: review, implications and directions for future research. Int J Prod Res 51(18):5413-5436. https://doi.org/10.1080/002075 43.2013.775523

Sethi S, Sorger G (1991) A theory of rolling horizon decision making. Ann Oper Res 29(1):387-415. https:// doi.org/10.1007/BF02283607

Simpson NC (2001) Questioning the relative virtues of dynamic lot sizing rules. Comput Oper Res 28(9):899-914. https://doi.org/10.1016/S0305-0548(00)00015-0

Stadtler H (2000) Improved rolling schedules for the dynamic single-level lot-sizing problem. Manag Sci 46(2):318-326. https://doi.org/10.1287/mnsc.46.2.318.11924

Stadtler H (2003) Multilevel lot sizing with setup times and multiple constrained resources: internally rolling schedules with lot-sizing windows. Oper Res 51(3):487-502. https://doi.org/10.1287/opre.51.3.487.1 4949

Tiacci L, Saetta S (2012) Demand forecasting, lot sizing and scheduling on a rolling horizon basis. Int J Prod Econ 140:803-814. https://doi.org/10.1016/j.ijpe.2012.02.007

Trigeiro WW (1987) A dual-cost heuristic for the capacitated lot sizing problem. IIE Trans 19(1):67-72. https://doi.org/10.1080/07408178708975371 
Xie J, Zhao X, Lee TS (2003) Freezing the master production schedule under single resource constraint and demand uncertainty. Int J Prod Econ 83(1):65-84. https://doi.org/10.1016/S0925-5273(02)00262-1

Yıldırım I, Tan B, Karaesmen F (2005) A multiperiod stochastic production planning and sourcing problem with service level constraints. OR Spectrum 27(2-3):471-489. https://doi.org/10.1007/s00291-005-0 203-0

Zhao X, Xie J (1998) Multilevel lot-sizing heuristics and freezing the master production schedule in material requirements planning systems. Prod Plan Control 9(4):371-384. https://doi.org/10.1080/095372898 234109

Zoller K, Robrade A (1988) Efficient heuristics for dynamic lot sizing. Int J Prod Res 26(2):249-265. https:// doi.org/10.1080/00207548808947857

Zulkafli NI, Kopanos GM (2017) Integrated condition-based planning of production and utility systems under uncertainty. J Clean Prod 167:776-805. https://doi.org/10.1016/j.jclepro.2017.08.152

Publisher's Note Springer Nature remains neutral with regard to jurisdictional claims in published maps and institutional affiliations. 